\title{
An analytical study of the determinants of foreign investment in Saudi Arabia "Saudi Vision 2030"
}

\author{
Sally El-Awady \\ Sarah Al-Mushayqih \\ Ebtehal Al-Oudah \\ Department of Economics, College of Business \& Economics \\ Qassim University, Kingdom of Saudi Arabia
}

\section{Keywords}

Determinants of Investment -Foreign Direct Investment (FDI) -GDP - Saudi Vision 2030.

\begin{abstract}
Attracting foreign direct investment (FDI) is considered one of the main challenges faced by economies. It is also one of the main factors that help develop the national economy since it contributes to increasing GDP growth rates in the host country, developing technical staff, creating jobs, transferring modern technology, and supporting competitive capacities. According to the Saudi Vision 2030, the ratio of FDI to GDP will be increased from 3.8\% to the global average of 5.7\%. The research problem is that there is a gap between the extent of current and hoped-for FDI. The research paper will discuss the following objectives: Exploring the current investment environment in KSA, shedding light on current legislations that are attractive for investment, identifying the most important determinants of investment in KSA, and testing the relationship between FDI inflows and economic factors affecting them.

The statistical descriptive analysis method was adopted, and a standard model was analyzed using the E-Views program. Secondary data were collected from the General Organization for Statistics, World Bank publications, and the UNCTAD database. The research hypotheses related to the existence of a significant relationship between the volume of FDI with GDP and the current investment laws were tested. In conclusion, the most important determinants of investment in KSA which have an impact are GDP growth rate, domestic investments, and natural gas reserves. Furthermore, there is an inverse relationship between government expenditure and inflation rate on the volume of FDI, which negatively affects the deficit of the state budget and the productive efficiency of different sectors. Also, the researchers have been recommended that there is a need to prepare the current investment environment to increase the attraction of FDI in KSA in order to achieve the Saudi Vision 2030 by increasing and diversifying GDP, developing programs to support local investment, reducing the government expenditure and the inflation rate, developing controls obliging foreign companies to transfer technology, train labor, and develop controls to take into account the cleanliness of the environment in the activities of FDI in the country.
\end{abstract}

\section{Introduction}

Attracting foreign direct investment (FDI) has become one of the main challenges faced by all economies.

There is no doubt that the Kingdom of Saudi Arabia is no different from the rest of the world in terms of its need for FDI. This is evident in the Saudi Vision 2030, announced in April 2016, which is based on three main axes, namely a vibrant society, a prosperous economy, and an ambitious homeland. The focus in the second axis is on the prosperous economy by creating opportunities for all through developing investment instruments to unleash the potential of economic sectors.

\section{Research Problem}

The research problem is the existence of a gap between current FDI and the hoped-for FDI in accordance with the Saudi Vision 2030. The research paper will consist of the following research questions:

1. To what extent does the current investment environment contribute to attracting foreign direct investment (FDI) to the Kingdom? 
2. To what extent do current investment laws and legislations contribute to attracting foreign investment? What is hoped for?

3. What are the most important determinants of investment in Saudi Arabia?

\section{Research Significance}

Foreign investment contributes mainly to establishing industrial cities and is highly emphasized by the Saudi Vision 2030. The significance of this research is clear because of the scarcity of studies on the field of foreign investment in Saudi Arabia, its determinants, and ways to attract it.

\section{Research Objectives}

The strategy of the Kingdom of Saudi Arabia Vision 2030 aims to increase the ratio of foreign direct investment in GDP from 3.8\% to the global average of 5.7\%. In order to meet this objective, the Kingdom seeks to develop strategies to prepare the internal investment environment to achieve the target rate. The research paper aims to achieve the following objectives:

1. Explore the current investment environment in the Kingdom of Saudi Arabia.

2. Focus on the current legislations that are attractive to investment.

3. Identify the most important determinants of investment in Saudi Arabia.

4. Test the statistical relationship between the flow of foreign direct investment and some of the economic factors affecting it.

\section{Research Hypotheses}

1. There is a statistically significant relationship between the volume of foreign direct investment and the volume of GDP.

2. There is a statistically significant relationship between increasing the volume of foreign direct investment and the current investment laws and legislations.

3. There is a statistically significant relationship between the volume of foreign direct investment and domestic investment, inflation rate, GDP growth rate, government expenditure, exchange rate, natural gas reserves, and the legislations and laws relating to foreign investment.

\section{Research Methodology}

The statistical descriptive analysis method was adopted to study the most important determinants of FDI in Saudi Arabia in accordance with the Saudi Vision 2030. A standard model was used and analyzed by the E-Views program. Secondary data were collected from the General Organization for Statistics, World Bank publications, the publications of the Secretariat General of the Gulf Cooperation Council (Department of Economic Affairs), and the UNCTAD database.

The equation can be formulated as follows:

$$
\begin{gathered}
\operatorname{LnY}_{t}=b_{1} \operatorname{Ln} x_{1 \mathrm{t}}+b_{2} \operatorname{Ln} x_{2 \mathrm{t}}+b_{3} \operatorname{Ln} x_{3 \mathrm{t}}+b_{4} \operatorname{Ln} x_{4 \mathrm{t}}+b_{5} \operatorname{Ln} x_{5 \mathrm{t}} \\
+b_{6} \operatorname{Ln} x_{6 \mathrm{t}}+b_{7} \mathrm{D}_{1 \mathrm{t}}+\mu_{t}
\end{gathered}
$$

\section{Research Structure}

The research consists of two sections:

Section I: The descriptive approach is used to review some of the components of foreign direct investment by analyzing its place in the previous literature.

Section 2: The standardized approach is used to evaluate the determinants of investment affecting foreign direct investment in the Kingdom of Saudi Arabia over the period 2000-2017.

\section{Theoretical Framework}

\section{First: Literature Review (previous studies)}

- Amin (2018) study examined the joint integration between the rates of inflation and foreign direct investment in Algeria over the period 1990-2016 using the Autoregressive Distributed Method ARDL. The study showed that there is a relationship between inflation rates and foreign direct investment.

- Kaloul (2017) study dealt with the attractiveness of Arab countries to foreign direct investment as a diagnostic study according to the index of the determinants of investment. It also recommended that decision makers and policy makers should periodically review the attractiveness of their countries, 
focusing on the strengths of each country and reducing weaknesses in order to ensure the continuous development of the environment and the determinants of investment.

- Fawzi (2015) study dealt with the competition between both developed and developing countries in order to attract the largest foreign direct investments. The study found that one of the most important advantages of FDI is the transfer of technology and the improvement of the efficiency of the use of human resources and the resources of the host country. The study also pointed out that interest rate reduction and the competition of non-banking financial institutions are among the most important factors driving short-term capital flows, which in turn leads to the formation of large foreign exchange reserves.

- Aljbory (2016) pointed out that the relationship between the investment environment and foreign direct investment is one of the planning methods that can help identify the main sectors attracting investment in order to achieve future goals to develop future strategies. The analytical model showed that the balance of payments and the exchange rate had no role, and so they were excluded from the model. Thus, the rate of GDP growth and inflation rates are the economic factors that affect attracting investments. But they are not at the required level because there are random variables that have a significant impact on repelling investments, including the political and security factors which were not included in the model, yet they are factors that repel foreign investment in Iraq. Despite the presence of natural and human resources, which are considered a positive indicator for attracting foreign investment, they are linked to security and political stability.

- Al-Madadha (2012) study aimed to investigate the interrelated effect of investments by analyzing the relationship between variables. The vector auto-regression model (VAR) was applied. It included two models. One model showed the relationship between GDP variables, FDI, and domestic investment, while the other showed the relationship between FDI and domestic investment.

- Haji and Najeeb (2010) study found that low inflation rates are of great importance in attracting many foreign direct investments. The quantitative analysis of all the countries in the sample proved that the relationship between privatization and FDI is proportional. It was revealed that the sign and the size of the parameter are negative. This does not mean that Poland did not attract foreign direct investment, but rather as a result of the use of privatization programs in the form of a comprehensive strategy. The study also proved that there is a positive relationship between technical developments and attracting more foreign capital benefiting the host country. The successful implementation of privatization programs leads to increased confidence in the soundness of economic reform, especially with respect to restructuring the productive sectors. This results in the increased acceleration of growth rates of the national economy. Using (R2), the researcher proved that privatization has a positive effect on attracting FDI.

- Demirhan and Masca (2008) study examined foreign investment in a group of developing countries as a dependent variable, while the independent variable included GDP per capita growth rate, inflation rate, labor cost per worker, degree of openness, and tax rate. The results of the study showed that the rate of inflation and the tax rate constitute a negative sign that is statistically significant.

- Omar (2007) study aimed at measuring the factors of foreign direct investment and analyzing those factors, especially the exports in a number of Arab countries. The study dealt with a number of economic variables, such as gross national product GNP, exports, inflation, government expenditure, and savings. The researcher used the quantitative method in the analysis. The study concluded that both the size of the market and the estimated export rate have a significant effect on foreign direct investment in most Arab countries, especially oil. The study also found out that the percentage of domestic saving to GNP is positive.

\section{Summary of Previous Studies}

In the previous studies, we note that they agreed on the fact that the rate of inflation has a negative impact on foreign direct investment, and that the reduction of the interest rate and competition of nonbanking financial institutions are the most important factors driving short-term capital flows, leading to the formation of large foreign reserves. The most important advantages of foreign direct investment are the transfer of technology and the improved efficiency of the use of human resources and the resources of the host country. The negative effects include the impact on the balance of payments and the structure of the domestic market. The growth rate of GDP and the ratio of domestic savings to the gross national 
product are considered among the most important economic factors affecting the attraction of investments, in addition to the political and security factors.

The previous studies also found a competitive relationship between foreign direct investment and domestic investment in the short term. The relationship between them develops to be a positive complementary relationship in the long term. A positive relationship has also been established between technical developments and the attraction of more foreign capital benefiting the host country.

\section{Second: Exploring the current investment environment in the Kingdom of Saudi Arabia Definition of Foreign Direct Investment (FDI)}

According to the International Monetary Fund, foreign investment is defined as "the kind of international investment that reflects the aim of obtaining a lasting interest by a resident entity of one economy (direct investor) in an enterprise that is resident in another economy (the direct investment enterprise). This "lasting interest" implies the existence of a long-term relationship between the direct investor and the direct investment enterprise.

\section{Characteristics of FDI}

FDI is considered a productive investment as a result of its optimal utilization of resources. It is also considered a means of creating jobs. According to the preliminary data of the Saudi Arabian Monetary Agency (2018), it is noted that foreign investments in the KSA increased by the end of the first quarter of 2018 to 1.494 trillion riyals, i.e., an annual increase of $12 \%$, equivalent to 159.43 billion riyals compared with the corresponding period in 2017.

\section{The current investment environment in Saudi Arabia and the factors attracting foreign direct investment}

The Saudi economy has a competitive environment for all economic activities, with an average annual growth rate of $4 \%$ over the last seven years. The Kingdom accounts for $25 \%$ of the Arab GDP and possesses the largest oil reserves. In addition, there are no restrictions imposed on foreign exchange, foreign transfer, and the transfer of capital and profits abroad. Saudi Arabia ranks 23rd among the 25 largest economies in the world and ranks first in the Middle East and North Africa. It also ranks 11th among 181 countries in the world index in terms of ease of doing business according to the World Bank's International Finance Corporation (IFC) Doing Business 2010 Report.

The most important factors characterizing the current investment environment of the Kingdom of Saudi Arabia which attract foreign investment include:

First: Announcing the Saudi Vision 2030 to diversify and expand the competitive capacities of the economy by setting specific targets to consolidate efforts and implement clear investment programs for 3 years through 12 programs.

Second: The Kingdom has an integrated infrastructure and a strategic location linking three continents with the largest port on the Red Sea, accounting for $80 \%$ of the maritime traffic.

Third: Providing opportunities to acquire real estate at competitive prices.

Fourth: The Kingdom is characterized by a young and skilled workforce, with a population of 32.5 million, about $50 \%$ of whom are youth. The Saudi workforce stands at about 5.7 million.

Fifth: The availability of a leading financial sector with a stable monetary system and a good banking sector. As per the Capital Market Authority (CMA), the Kingdom has the largest capital market in the Middle East and North Africa.

\section{Third: Current legislation attractive to investment in Saudi Arabia and what they are hoped to achieve}

The Saudi government has granted tax concessions to a number of less developed regions in the Kingdom to attract more investments. The tax concessions will be for ten years from the date of the beginning of any project. The tax incentives include the following advantages (Investment Highlights: A special report by SAGIA - Summer 2019):

- $50 \%$ discount on the annual training costs for Saudi labor and the annual wages paid to Saudis.

- Additional discounts are granted if the capital invested exceeds SAR 1 million and if more than five Saudi nationals are employed for a minimum of one year in jobs of a technical or administrative nature. 
The Kingdom aspires to achieve a number of global advanced positions in the coming years in the field of investment competitiveness.

\section{Fourth: The most important determinants of investment in Saudi Arabia}

The determinants are defined as the overall conditions or economic, political, social, and procedural conditions that may affect the chances of success of an investment project in a particular country.

Determinants are considered mandatory for attracting foreign investment. They can be divided into two main determinants:

1. Political stability: The political stability in the host country is an indispensable prerequisite for investment.

2. Economic stability: The economic stability implies achieving a set of macroeconomic balances and providing appropriate opportunities for the success of the investment.

Figure.1. Determinants of Attracting Foreign Direct Investment during 2000-2017.

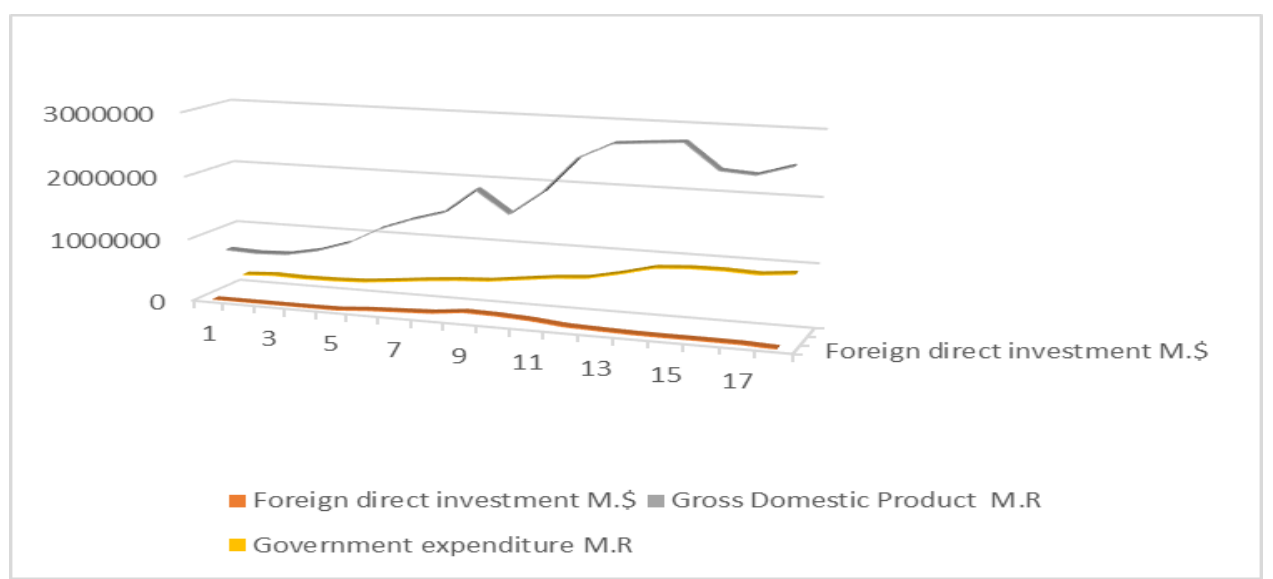

\section{The analytical study}

In order to measure the relationship between foreign direct investment and the economic growth rate, a standard model was created to analyze the long-term relationship between the development of foreign investment activity and the growth rate in Saudi Arabia. The model was based on the theory of cointegration, which was presented and statistically proved by Engel and Granger (1987). The study model is presented in the following equation:

$\operatorname{LnY} Y_{t}=b_{1} \operatorname{Ln} x_{1 \mathrm{t}}+b_{2} \operatorname{Ln} x_{2 \mathrm{t}}+b_{3} \operatorname{Ln} x_{3 \mathrm{t}}+b_{4} \operatorname{Ln} x_{4 \mathrm{t}}+b_{5} \operatorname{Ln} x_{5 t}$

Where:

$$
+b_{6} \operatorname{Ln} x_{6 t}+b_{7} D_{1 t}+\mu_{t} \ldots \ldots \ldots \ldots \ldots \ldots \ldots \ldots \ldots(1)
$$

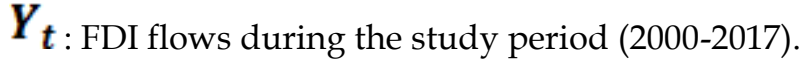

$x_{1 t}$ : GDP growth rate during the study period at constant prices.

$\boldsymbol{x}_{\mathbf{2 t}}$ : Domestic investment, which is measured by gross fixed capital formation to GDP during the study period.

$\boldsymbol{x}_{3 \mathrm{t}}$ : Inflation rate during the study period.

$\boldsymbol{x}_{\mathbf{4 t}}$ : Government expenditure during the study period.

$x_{5} t$ : Natural gas reserves during the study period.

$\boldsymbol{x}_{6 \mathrm{t}}$ : Exchange rate during the study period.

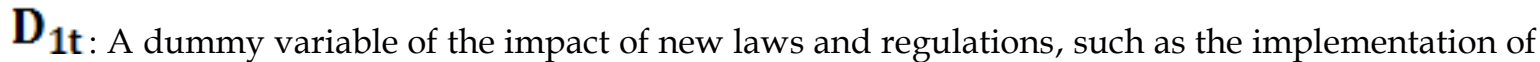
the sales tax and incentives for encouraging FDI since 2010 in the Kingdom. This variable is zero during the period 2000-2009 and takes the value of 1 during the period 2000-2017.

$\boldsymbol{\mu}_{\boldsymbol{t}}$ : Represents the random error element 
The method of measuring the relationships of the co-integration between the variables according to the methodology of Engel and Granger (Engle \& Granger 1987) is based on processing data and the stationary test of time series. The logarithm of the data was calculated in order to reduce the abnormal values within the data and variables of the study. After that, the tests of the root unit test and the PhilpPerron test were carried out to test the stationarity of the time series of the variables used in the study. The results that were obtained are shown in the following model:

Table (1): The effect of the economic variables under study on foreign investment in the Kingdom of Saudi Arabia during the period 2000-2017.

\begin{tabular}{|l|l|l|l|l|}
\hline $\begin{array}{l}\text { Dependent Variable: } \\
\text { Direct Foreign Investment }\end{array}$ & B & Std & T-value & P-value \\
\hline Constant & 0.0722 & 0.062 & 2.66 & 0.023 \\
\hline GDP Growth rate & 0.0125 & 0.007 & 5.13 & 0.001 \\
\hline Domestic investment & 0.059 & 0.046 & 2.98 & 0.003 \\
\hline Inflation rate & $0.061-$ & 0.051 & -3.17 & 0.001 \\
\hline Government expenditure & $0.014-$ & 0.011 & -5.11 & 0.000 \\
\hline Natural gas reserves & 0.075 & 0.058 & 2.74 & 0.026 \\
\hline Exchange rate & 12.115 & 2.17 & 0.169 & 0.989 \\
\hline $\begin{array}{l}\text { Foreign investment legislations and laws related to } \\
\text { foreign investment (dummy variable) }\end{array}$ & 0.152 & 0.094 & 3.01 & 0.018 \\
\hline$R^{2}$ value & 0.89 & & \\
\hline Adjusted R value & 0.84 & & \\
\hline \multicolumn{1}{|l|}{1.52} \\
\hline
\end{tabular}

Source: Results of data analysis on E-Views

\section{Results and discussions}

The values of the model parameters and their signs indicate that some of the variables used in the model showed the anticipated trends based on the economic theory, while others showed different trends compared with what was expected. This can be illustrated as follows:

1. Table (1) shows a statistically significant relationship between the growth rate of GDP $\left(X_{1}\right)$ and the volume of foreign direct investment in the Kingdom. It is clear from the positive signs of the estimated parameter of the variable that there is a direct relationship between them. This can be explained by when GDP growth increase by one unit, the volume of foreign investment will increase by 0.0125 unit. This result is consistent with the results of previous economic literature. Increasing GDP drives economic development and diversifies the production base. This is what the Saudi 2030 Vision aims to achieve.

2. Table (1) also shows a statistically significant relationship between the local investment, which is measured by the ratio of gross fixed capital formation to gross domestic product $\left(\mathrm{X}_{2}\right)$, and the volume of foreign direct investment in the Kingdom. This can be explained by when domestic investment increase by one unit, the volume of foreign investment will increase by 0.059 unit. This indicates that more domestic investment, represented in increasing the accumulation of fixed capital results, leads to more infrastructures that are needed to increase production and thus increase employment and reduce unemployment. This in turn is reflected in the increase in the average per capita income, which encourages the foreign investor to increase his investments and projects inside the Kingdom.

3. Table (1) indicates that there is a statistically significant relationship between the inflation rate and the volume of foreign direct investment in the Kingdom. The negative sign of the inflation rate $\left(\mathrm{X}_{3}\right)$ is consistent with the economic theory, as it indicates that there is an inverse relationship between the inflation rate and the volume of foreign direct investment. This makes foreign investors reluctant to increase their investments inside the country. As for the magnitude of the impact, the increase in inflation by one unit leads to the reduction of FDI by about 0.061 unit.

4. Table (1) also shows a statistically significant inverse relationship between the net government expenditure and the volume of FDI in the Kingdom. According to economic theory, further government expenditure $\left(\mathrm{X}_{4}\right)$, which indicates a budget deficit, is expected to reduce FDI in the economy. The value of 
the parameter indicates that increasing government expenditure by one unit leads to reducing FDI by about 0.014 unit.

5. Table (1) shows a statistically significant relationship between natural gas reserves and the volume of foreign direct investment in the Kingdom. The positive sign $\left(\mathrm{X}_{5}\right)$ is consistent with the economic theory, which indicates that there is a direct relationship between natural gas reserves and the volume of foreign direct investment. As for the magnitude of the impact, the increase in natural gas reserves by one unit leads to an increase in FDI by about 0.075 unit.

6. Table (1) emphasizes the existence of a statistically insignificant relationship between the exchange rate $\left(X_{6}\right)$ and the volume of foreign direct investment in the Kingdom. The stability of the Saudi riyal exchange rate against the dollar is a two-way determinant, as this may be reassuring to the investor to consummate commercial transactions.

7. Using a dummy variable reflecting the legislations and laws related to foreign investment $\left(\mathrm{D}_{1}\right)$, the positive sign refers to the expected direct relations between the variable under study and the volume of foreign direct investment in the Kingdom through the strategies included in the Saudi 2030 Vision to attract foreign investment with the help a system of laws and legislation adopted by the parties supporting investment.

8. The value of $\mathrm{R}^{2}$ means that the independent variables account for $89 \%$ of the change in the dependent variable, while the remaining $11 \%$ is attributed to other factors explained by the random error in the model. The value of Adjusted $\mathrm{R}^{2}$ was about $84 \%$, indicating a high explanatory power of the model. The value of D.W was 1.52, thus indicating that it is expected that the model would not suffer from the problem of the self-correlation between random errors.

From the above analysis, the research paper reached the following conclusions:

1. There are positive factors contributing to the creation of an attractive investment environment for foreign direct investment in the Kingdom of Saudi Arabia.

2. The legislative and executive authorities are working within the Saudi Vision 2030 to modernize and develop existing investment laws and legislations in order to attract foreign investment.

3. The most important determinants of investment in Saudi Arabia that have a statistically significant impact are GDP growth rate, domestic investments, and natural gas reserves.

4. There is a significant inverse relationship between government expenditure and the volume of foreign direct investment, which negatively affects the deficit of the state budget. This was discussed in the Saudi Vision 2030 which called for privatization programs for the public sector.

5. There is a significant inverse relationship between the rate of inflation and the volume of foreign direct investment, which negatively affects the productive efficiency of different sectors.

\section{Recommendations}

1. There is a need to prepare the current investment environment to increase the attraction of foreign direct investment in Saudi Arabia in order to achieve the Saudi Vision 2030.

2. Priority must be given to investment laws and regulations that support and attract foreign investment, in addition to creating specialized and diverse committees to study obstacles and problems that may face the investment process in the Kingdom.

3. Increasing and diversifying GDP must be taken into account, as this has a positive impact on FDI flows.

4. There is a need to develop programs to support and encourage local investment, especially small and micro-enterprises, and increase support and funding for women's projects.

5. A strategy must be developed in order to control the reduction of government expenditure and the inflation rate, as this has a negative impact on FDI flows.

6. There is a need to study the impact of the stability of the exchange rate on the economic structure of Saudi Arabia.

7. There is a need to direct FDI towards the economic and political sectors and activities according to a system of priorities that includes achieving sustainable development and giving priority to the participation of national capital with foreign capital. 
8. There is a need to develop controls obliging foreign companies to transfer technology, train labour, and develop controls to take into account the cleanliness of the environment in the activities of foreign direct investment in the country.

\section{References}

Aljbory, A 2016, 'The impact of the investment environment in attracting foreign direct investment on Iraq model for the period (2003 - 2013)', Al-Qadisiyah Journal of Qadisiya Administrative and Economic Sciences, vol. 18, no. 2, pp. 144-163.

Amin, T 2018. 'Examining the joint integration between inflation and FDI in Algeria for the period (1990-2016) using ARDL self-regression model, Horizons for Economic Studies, vol. 3, no. 2, pp. 263-276.

Demirhan, E \& Masca, M 2008, 'Determinants of foreign direct investment flows to developing countries: A cross sectional analysis', Prague Economic Papers, University of Economics, Prague, vol. 17, no. 4, pp. 356-369.

El-Mdadha, R 2012, "The Effectiveness of Foreign Investments on Economic Activity in Jordan fot the period (1980 - 2010) Using Time Series Analysis, Master Thesis, Mu'tah University, Jordan.

Engle, RF \& Grange, CWJ 1987, 'Co-integration and error correction: representation, estimation, and testing', Econometrica, vol. 55, no. 2, pp. 251-276.

Fawzi, SO 2015, The role of foreign direct investment in meeting the requirements of economic development in the GCC Countries, PhD thesis, Department of Economics, Faculty of Commerce, Ain Shams University, Egypt.

Haji, A \& Najeeb, S 2010, 'A comparative study of a sample of countries according to the levels of manufacturing', TANMIYAT AL-RAFIDAIN, vol. 32, no. 97, pp. 335-357.

Investment Highlights: A special report by SAGIA - Summer 2019, Invest Saudi, viewed 1 Feb 2020, < https://investsaudi.sa/en/news/summer-investment-highlight/>

Kaloul, S 2017, 'The attractiveness of Arab countries to foreign direct investment as a diagnostic study according to the index of measuring the determinants of investment', Arab Monetary Fund, no. 36, pp. 1-50.

MOF welcomes the IMF's 2019 Article IV Consultation Report 2019, Ministry of Finance, viewed 15 Jan 2020, < https://www.mof.gov.sa/en/mediacenter/news/Pages/News_09092019_1.aspx>

Omar, D 2007, 'The effect of exports on direct foreign investment follow in selected Arab countries', TANMIYAT AL-RAFIDAIN, vol. 29, no. 86, pp. 128-146.

Saudi Arabian Monetary Authority (2018) 54th Annual Report 1439H - 2018. Available at: http://www.sama.gov.sa/en-US/EconomicReports/AnnualReport/Fifty\%20Fourth\%20Annual\%20Report.pdf (Accessed: 17 Jan 2020). 